\title{
SEIZURES AND EPILEPSY IN ELDERLY: A TERTIARY CARE CENTRE HOSPITAL BASED STUDY
}

\author{
Binod Sarmah1, Parampreet Singh Kharbandaㄹ, Sudesh Prabhakar ${ }^{3}$
}

${ }^{1}$ Assistant Professor, Department of Neurology, Assam Medical College \& Hospital, Dibrugarh.

${ }^{2}$ Professor, Department of Neurology, Postgraduate Institute of Medical Education \& Research, Chandigarh.

${ }^{3}$ Former Professor, Department of Neurology, Postgraduate Institute of Medical Education \& Research, Chandigarh.

\begin{abstract}
Seizure and epilepsy in elderly compared with younger adult population, differs in etiology, clinical presentation and prognosis. Management of epilepsy in elderly individual can be complicated by various factors, like concurrent medical illnesses, drug interactions, changes in pharmacokinetics and altered central nervous system pharmacodynamics. Adverse effects of antiepileptic drugs are also high in elderly people.

METHODS: One hundred and fifty-four patients with seizures and epilepsies and age more than 60 years were included in the study. All enrolled patients underwent detailed clinical history, laboratory investigations and imaging studies. Classification of seizure was done as per ILAE classification 1981/1989.

RESULTS: A total of 154 patients aged 60 or more were included in the study, out of which $102(66.2 \%)$ males and 52 (33.76\%) females. One hundred and eight (70.1\%) patients started having seizures after 60 years of age and remaining patients (29.9\%) had seizure onset before 60 years. Symptomatic epilepsies were the most common type of epilepsy (78.6\%) and partial seizures were the most common type of seizure in the study (51.9\%). Cerebrovascular diseases were the most common cause of seizures and epilepsies in elderly (44.8\%) followed by CNS infections $(11.7 \%)$, metabolic factors $(7.8 \%)$, brain tumors (6.5\%), head injury (6.5\%) and hippocampal sclerosis (4.6\%). EEGs were abnormal in 34.9\% patients, whereas CT brain (n=154) and MRI brain $(n=102)$ were abnormal in $61.7 \%$ and $59.7 \%$ respectively. Majority of patients had received only one AED at the time of inclusion (59.1\%) in the study. Phenytoin was the most common antiepileptic that was used for the treatment of seizures (74.7\%). Overall incidence of AED induced adverse effects was 22.1\%. Most common adverse effect was drowsiness (13.6\%) followed by decrease memory (5.2\%) and tremor (3.2\%). Incidence of adverse reactions was highest among phenobarbitone treated group (33.3\%).
\end{abstract}

KEYWORDS: Elderly, Seizures, Epilepsy, Idiopathic, Symptomatic.

HOW TO CITE THIS ARTICLE: Binod Sarmah, Parampreet Singh Kharbanda, Sudesh Prabhakar. "Seizures and Epilepsy in Elderly: A Tertiary Care Centre Hospital Based Study.” Journal of Evolution of Medical and Dental Sciences 2015; Vol. 4, Issue 93, November 19; Page: 15880-15884, DOI: 10.14260/jemds/2015/2306.

INTRODUCTION: Seizures occur in an age dependent, bimodal pattern with an initial peak in incidence during the first year of life and then a sustained rise in incidence beginning around the age of 60 years that surpasses incidence at all other ages. ${ }^{1-3}$ As people are surviving longer, the average age of the population further rises increasing the number of elderly individuals at risk for developing seizures and epilepsy. ${ }^{4}$ Studies have shown approximately $1-2 \%$ of the aging population has epilepsy. ${ }^{5}$ At age over 75 years, it increases by two to three fold as compared to younger age group with greatest prevalence is in elders over 85 years..$^{5-7}$ Epilepsy in elderly compared with younger adult population differs in etiology, clinical presentation and prognosis.

Management of epilepsy in elderly individual can be complicated by many factors including concurrent medical illnesses, drug interactions, changes in pharmacokinetics and altered central nervous system pharmacodynamics. Adverse effects of anti-epileptic drugs and seizures related deaths are also high in elderly people.

Financial or Other, Competing Interest: None

Submission 16-11-2015, Peer Review 17-11-2015,

Acceptance 18-11-2015, Published 19-11-2015.

Corresponding Author:

Dr. Binod Sarmah,

Assistant Professor, Department of Neurology,

Assam Medical College \& Hospital,

Dibrugarh-786002.

E-mail: b_sarmah2007@yahoo.com

DOI:10.14260/jemds/2015/2306.
In Asia, there are limited published data on seizures and epilepsy in elderly. In this paper, we are trying to report our findings of study on elderly epilepsy.

METHODS: This prospective study was conducted in a tertiary care centre in North India. Patients with seizures and epilepsies and age more than 60 years were included in the study. All enrolled patients underwent detailed clinical history as per standard seizures questionnaire, laboratory investigations and imaging studies. Classification of seizure and epilepsies were done as per ILAE classification $1981 / 1989.8$

\section{RESULTS:}

Clinical Characteristics: A total of 154 patients aged 60 or more (Mean $66.25 \pm 5.95$ years) were included in the study, out of which $102(66.2 \%)$ males and 52 (33.76\%) females. Out of 154 patients, 108 (70.1\%) patients started having seizures after 60 years of age and remaining patients (29.9\%) had seizure onset before 60 years and mean age of onset was $58.72 \pm 6.35$ years. Mean duration of seizure disorders was $7.66 \pm 14.58$ years, ranging from 1 day to 55 years. Most of the patients $(46.1 \%)$ had seizures for more than 2 years. Among the 154 patients, $42(27.3 \%)$ had acute symptomatic seizures and remaining $112(72.7 \%)$ had unprovoked seizures (Epilepsy). Majority of patients (51.9\%) had partial seizures followed by primary generalized tonic-clonic seizures in 74 (48.1\%). 
Table 1: Clinical profiles of elderly patients with seizures and epilepsy. Table showing demographic data, age at seizure onset, duration of seizures and epilepsy, types of seizures, epilepsy syndromes and postictal events.

\begin{tabular}{|c|c|c|c|}
\hline Total Enrolled Patients & 154 & Types of Seizures & \\
\hline Mean age & $\begin{array}{c}66.25 \pm 5.95 \text { yrs. } \\
\text { (Range } 60-87 \text { yrs.) }\end{array}$ & Simple partial Seizures & $7(4.5 \%)$ \\
\hline Male & $102(66.2 \%)$ & Complex partial Seizures & $14(9.0 \%)$ \\
\hline Female & $52(33.76 \%)$ & Partial Seizures with secondary generalization & $59(38.4 \%)$ \\
\hline Age at Seizure onset & & Primary generalized tonic-clonic Seizures & $74(48.1 \%)$ \\
\hline Mean & $58.72 \pm 6.35$ years & Acute Symptomatic Seizures & $42(27.3 \%)$ \\
\hline$<30$ yrs. & $16(10.4 \%)$ & Epilepsy syndromes & $112(72.7 \%)$ \\
\hline $30-60$ yrs. & $30(19.5 \%)$ & Symptomatic Epilepsy* & $88(78.6 \%)$ \\
\hline$\geq 60$ yrs. & $108(70.1 \%)$ & Idiopathic Epilepsy* & $12(10.7 \%)$ \\
\hline \multirow[t]{2}{*}{ Duration of Seizures } & & Cryptogenic* & $10(8.9 \%)$ \\
\hline & & Unclassified & $2(1.8 \%)$ \\
\hline$<1$ month & $50(32.5 \%)$ & Postictal period & \\
\hline 1month-1year & $15(9.8 \%)$ & Confusion & $101(65.58 \%)$ \\
\hline $1-2$ yrs. & $18(11.6 \%)$ & Neurodeficit & $54(35.06 \%)$ \\
\hline \multirow[t]{2}{*}{$\geq 2$ yrs. } & $71(46.1 \%)$ & Headache & $23(14.94 \%)$ \\
\hline & & Loss of consciousness & $16(19.24 \%)$ \\
\hline
\end{tabular}

\begin{tabular}{|c|c|c|c|}
\hline \multicolumn{4}{|c|}{ Table 2: Abnormalities detected in EEG, Computed Tomography and MRI brain studies. } \\
\multicolumn{2}{|c|}{ CT brain was done in all 154 patients, whereas EEG and MRI brain was done in 146 and 102 patients respectively. } \\
\hline Investigations & Number of Patients & Investigations & Number of Patients \\
\hline EEG & $18(12.3 \%)$ & MRI brain & $29(28.5 \%)$ \\
\hline Focal slowing & $30(20.5 \%)$ & Infarct & $3(2.9 \%)$ \\
\hline Generalized slowing & $3(2.1 \%)$ & Tumors & $9(8.9 \%)$ \\
\hline Epileptiform discharges & $95(65.1 \%)$ & Cerebral atrophy & $3(2.9 \%)$ \\
\hline Normal & & Granulomatous lesions & $7(6.9 \%)$ \\
\hline CT brain & $56(36.4 \%)$ & Hippocampal sclerosis & $7(6.9 \%)$ \\
\hline Infarct & $11(7.4 \%)$ & Hygroma & $1(0.9 \%)$ \\
\hline ICH & $9(5.8 \%)$ & Microangiopathic changes & $1(0.9 \%)$ \\
\hline Tumors & $9(5.8 \%)$ & AVM & $1(0.9 \%)$ \\
\hline Gliotic foci & $8(5.1 \%)$ & Normal & $41(40.3 \%)$ \\
\hline Granulomatous lesions & $2(1.2 \%)$ & & \\
\hline Cerebral atrophy & $59(38.3 \%)$ & & \\
\hline
\end{tabular}

Out of 112 patients with epilepsy, symptomatic epilepsy was by far the most common type of epilepsy in this study (78.6\%) followed by idiopathic epilepsy 12 (10.7\%) and cryptogenic epilepsy 10 (8.9\%). The clinical characteristics of enrolled patients are shown in Table1.

Etiology of Seizures: Etiologies of seizures were known in $129(83.8 \%)$ patients. The commonest cause of seizures was stroke $(44.8 \%)$ followed by CNS infections (11.7\%), metabolic factors $(7.8 \%)$, brain tumors $(6.5 \%)$, head injury (6.5\%) and hippocampal sclerosis (4.6\%). Dementia, cystic hygroma and arterio-venous malformation was seen in one patient each $(0.6 \%)$. Twenty five $(16.3 \%)$ patients had either idiopathic or cryptogenic seizures. Figure 1 showing various etiologies of seizures in the studied population.

EEG and Neuroimaging: EEG was available in 146 patients, out of whom abnormalities were seen in 56 (34.9\%) patients. Most common abnormality was generalized slowing (20.5\%), followed by focal slowing (12.3\%) and spike-wave discharges $(2.1 \%)$. CT brain was done in all patients and abnormalities were seen in $95(61.7 \%)$ patients.
Most common abnormality was infarct $58.9 \%$ followed by intracranial haemorrhage $(11.6 \%)$, tumors $(9.5 \%)$, gliotic foci $(9.5 \%)$ and granulomatous lesions $(8.4 \%)$.

One hundred and two patients underwent MRI brain study, out of which 61 (59.7\%) patients had abnormal findings. Infarct was the most common MRI abnormality $(47.6 \%)$ followed by tumors (14.8\%), hippocampal sclerosis (11.5\%), granulomatous lesions (11.5\%), intracranial haemorrhage $(4.9 \%)$, cerebral atrophy $(4.9 \%)$ and others $4.8 \%$. Table 2 showing various EEG and neuroimaging findings in the present study.

Antiepileptic Therapy: During entire course of illness, 91 $(59.1 \%)$ patients received only one antiepileptic drug, 44 (28.6\%) patients received two antiepileptic drugs and remaining $19(12.3 \%)$ patients received more than two antiepileptic drugs. The most common antiepileptic drug used for the treatment of seizures was Phenytoin 115 (74.4\%), whereas Carbamazepine was used in 28 (18.2\%) patients followed by Phenobarbitone 21 (13.6\%), Sodium valproate $18(11.7 \%)$, Levetiracetam 9 (5.8\%), Lamotrigine 1 $(0.7 \%)$, Divalproex sodium $1(0.7 \%)$, and Oxcarbazepine 1 (0.7\%). Clobazam was combined with other antiepileptic drugs in $46(29.9 \%)$ patients. 
Drug levels of phenytoin (Mean 11.8 \pm 2.6 ), phenobarbitone (Mean 19.9 \pm 2.4 ), carbamazepine (Mean $5.4 \pm 1.3$ ) and sodium valproate (Mean $58.6 \pm 4.3$ ) were done in $52,16,15$ and 15 number of patients respectively.

Overall $34(22.1 \%)$ patients experienced different types of adverse effects due to antiepileptic therapy. Drowsiness was the most common (13.6\%) adverse effect followed by decrease memory (5.2\%) and tremor (3.2\%). Incidence of adverse effect was maximum in phenobarbitone treated group $(33.3 \%)$ followed by clobazam (23.9\%), sodium valproate $(22.2 \%)$, carbamazepine $(17.9 \%)$ and phenytoin (14.8\%) group. Different profiles of antiepileptic drug therapy (Mean dose, mean duration of therapy, drug levels and incidence of adverse effects) are shown in Table 3.

\begin{tabular}{|c|c|c|c|c|c|}
\hline \multicolumn{5}{|c|}{ Table 3: Antiepileptic drug profiles of the study. Table showing total recipient, mean dose, } \\
mean duration of therapy, mean drug level and incidence of adverse effects of antiepileptic drugs.
\end{tabular}

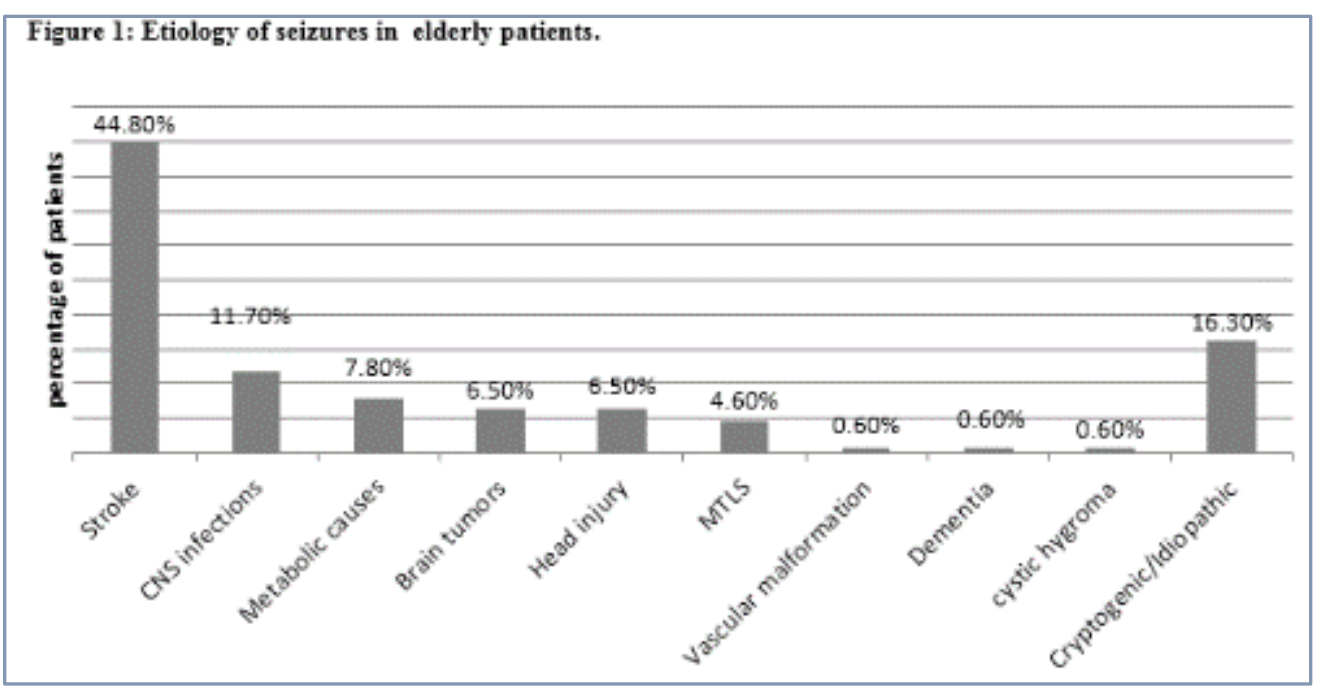

DISCUSSION: The demographic trend clearly shows that the population of the world is aging, and by 2025 in many developed countries the proportion of the population older than 60 years will be more than $30 \% .{ }^{9}$

The incidence of a "First" seizure has been reported to be 52 to 59 per 100,000 in persons 40 to 59 years of age, but goes up to 127 per 100,000 in those 60 years and older. ${ }^{10}$ Seizures and epilepsy will become an important and common clinical problem in elderly. Major known causes of seizures in this age group are cerebrovascular disease, brain tumors, CNS infections, head trauma, Alzheimer's disease and various toxic-metabolic syndromes such as non-ketotic hyperglycemia and drug toxicity. ${ }^{11,12}$ Recognition of seizures in elderly may be complicated by relatively unique clinical presentation and differential diagnosis. Pharmacological treatment is complicated by age-related changes in pharmacokinetics and pharmacodynamics and various drug interactions. We undertook this study to assess the clinical profile of epilepsy in elderly. In this study, we evaluated 154 patients and categorized them into different seizure and epilepsy types.

Our finding on male preponderance of seizures and epilepsies in elderly was also previously described by Hiyoshi et al. ${ }^{13}$ Prolonged postictal confusion was the most common postictal phenomenon found in this study, which was similar to previous study done by Stefan et al. ${ }^{14}$ 
Partial seizures are the most common type of seizure seen among the elderly patients with seizures. In a study by Hiyoshi et al., $76.3 \%$ elderly patients with seizures have partial seizures and similar findings were also reported by Sundaram. Sundaram in his study of 67 patients with epilepsy found partial seizures in $45(67 \%)$ and generalized seizures in 22 (33\%) patients. 15

A study by Ettinger et al., found equal percentage of partial and generalized seizures in 82 elderly patients with new-onset seizures. In this study, $33(41 \%)$ had acute symptomatic seizures followed by remote symptomatic seizures in 32 (40\%), progressive encephalopathy in 9 (11\%), and idiopathic in $6(8 \%) .16$ In our study, acute symptomatic seizures were seen in $42(27.3 \%)$ and the remaining $112(72.7 \%)$ patients had unprovoked seizures (Epilepsy). Symptomatic epilepsies are the most common type of epilepsy in elderly, as previously reported in various studies was also found in our study. ${ }^{14,17,19}$ In a study by Hauser et al., reported symptomatic epilepsy in 55\% patients and cryptogenic/idiopathic epilepsy in $45 \%{ }^{6}$

Cerebrovascular diseases continue to be a most common cause of seizures and epilepsy in elderly followed by metabolic, infections, trauma, tumors and others.12,19 In our study, Cerebrovascular diseases was found to be the commonest cause of seizures $(44.8 \%)$ in elderly individuals, which was similar to the previously reported studies.6,11 Though EEG is the most commonly performed investigation in patients with seizures, it is less specific and sensitive than neuroimaging. ${ }^{20}$ With advancing age, $12-38 \%$ of healthy individuals develop EEG abnormalities. Therefore, diagnosis of seizure disorder in elderly should not be made solely on EEG findings, but can be useful for identifying the seizure type.

About $20-40 \%$ elderly patients with seizures can have abnormal interictal EEGs. ${ }^{21,23}$ In the VA Cooperative Study, 593 patients underwent EEG study where they found normal EEG in $31.3 \%$ patients and nonspecific abnormalities in many patients. $^{24,25}$ In our study, EEG abnormalities were seen in 56 (34.9\%) patients which was similar to the previously reported studies. Neuroimagings are the most important investigations in the evaluation of patients with seizures which can detect intracerebral lesions.

Magnetic resonance imaging (MRI) is the gold standard, detecting pathology more accurately than computerized tomography. In the VA Cooperative Study, 82\% elderly patients with seizures had abnormal CT and MRI findings out of which $42.6 \%$ patients had cerebrovascular accident and $40.9 \%$ displayed small-vessel disease. ${ }^{24}$ Another study by Christine et al., found cortical infarcts in $20 \%$ cases followed by tumor (10\%), cryptic arteriovenous malformation (4\%) and mesiotemporal sclerosis (2\%). ${ }^{26}$ In our study, CT brain was abnormal in $95(61.7 \%)$ patients and 61 (59.7\%) patients had abnormal MRI brain. This finding of neuroimaging was due to selection of patients for MRI brain study. MRI brain was done in many patients who were having normal CT brain and showed abnormal MRI sudy.

To select the appropriate drug and dosage for each elderly individual, a variety of issues must be considered. Many of the challenges posed by treating elderly patients are due to agerelated changes in pharmacokinetics of antiepileptic drugs (AEDs). There are significant changes in absorption, distribution, metabolism, and excretion of AEDs and other medications in elderly patients. There is significant risk of drug interaction among elderly due to various coprescriptions. ${ }^{27}$ Approximately, $60-70 \%$ of elderly epileptics can be adequately controlled with mono-therapy; $50-60 \%$ of those failing mono-therapy can be satisfactorily treated with an alternate second drug. ${ }^{13}$ Studies have shown approximately $15-25 \%$ elderly epileptics experienced adverse reactions to antiepileptics, especially older AEDs. ${ }^{28,30}$ In our study, $91(59.1 \%)$ patients were on monotherapy and remaining $63(40.9 \%)$ patients received two or more antiepileptic drugs. Overall percentage of adverse effect was $22.1 \%$ and drowsiness was most common type of side effects encountered by the patients.

CONCLUSION: Seizures and epilepsies in elderly, compared with the younger adult population, differ in etiology, clinical presentation, and prognosis. Despite the rising prevalence and potentially profound physical and psychosocial effects of new-onset epilepsy in elderly people, this disorder has received surprisingly little research focus. Antiepileptic drugs therapy in elderly requires pharmacokinetics and pharmacodynamic adjustment due to the physiological changes associated with aging and frequent co-morbid conditions. There is increasing consensus that future treatment strategies should move not only to control of seizures, but also to prevent the occurrence of seizures in elderly.

\section{REFERENCES:}

1. Sander JW, Shorvon SD. Epidemiology of the epilepsies. J Neurol Neurosurg. Psychiatry. 1996; 61(5):433-43.

2. De la Court A, Breteler MM, Meinardi H, Hauser WA, Hofman A. Prevalence of epilepsy in the elderly: The Rotterdam Study. Epilepsia.1996; 37(2):141-47.

3. Hauser WA. Seizure disorders: The changes with age. Epilepsia.1992; 33 (suppl4):S6-S14.

4. Wallace H, Shorvan S, Tallis R. Age-specific incidence and prevalence rates of treated epilepsy in an unselected population of 2,052,922 and age-specific fertility rates of women with epilepsy. Lancet 1998; 352:1970-73.

5. Hauser WA, Annegers JF, Kurland LT. Incidence of epilepsy and unprovoked seizures in Rochester, Minnesota 1935-1984. Epilepsia 1993; 34:453-58.

6. Sander JW, Hart YM, Johnson AL, Shorvon SD. National General Practice Study of Epilepsy: Newly diagnosed epileptic seizures in general population. Lancet 1990; 336:1267-70.

7. Ramsay RE, Rowan AJ, Pryor FM. Special considerations in treating the elderly patient with epilepsy. Neurology 2004; 62:S24-S29.

8. Fisher RS, Walter van Emde Boas et al. Epileptic Seizures and Epilepsy: Definitions Proposed by the International League against Epilepsy (ILAE) and the International Bureau for Epilepsy (IBE). Epilepsia 2005; 46(4):470-72.

9. US Bureau of the Census, 2004.

10. Boston MA. Seizures and Epilepsy in the Elderly. Butterworth- Heinemann, 1997:7-20.

11. Luhdorf K, Jensen LK, Plesner AM. Etiology of seizures in the elderly. Epilepsia 1986; 27 (4): 458- 63. 
12. Loiseau J, Loiseau P, Duche B, et al. A survey of epileptic disorders in southwest France: Seizures in elderly patients. Ann Neurol. 1990; 27:232-37.

13. Hiyoshi T. Yagi K. Epilepsy in the elderly. Epilepsia 2000; 41(suppl 9):31-35.

14. Stefan H, May T.W et al. Epilepsy in elderly: comparing clinical characteristics with younger patients. Acta Neurol Scand 2014; 129:283-293.

15. Sundaram MBM. Etiology and Patterns of Seizures in the Elderly. Neuroepidemiology 1989; 8:234-38. Ettinger, A B. Shinnar, S. New-onset seizures in an elderly hospitalized population. Neurology1993; 43: 489-92.

16. Roberts M, Godfrey J, Caird F. Epileptic seizures in elderly: Aetiology and types of seizure. Age Ageing 1982; 11: 24-28.

17. So EL, Annegers JF, Hauser WA et. al. Population-based study of seizure disorders after cerebral infarction. Neurology.1996; 46:350-55.

18. Sung CY and Chu NS. Epileptic Seizures in Elderly People Aetiology and Seizure Type. Age Ageing. 1990; 19:25-30.

19. Drury I, Beydoun A, Arbor A. Seizures and epilepsy in elderly revisited. Arch Intern Med 1998; 158: 99-100.

20. Hopkins A, German A, Clarke C. The first seizure in adult life; value of clinical features, EEG and CT scanning in prediction of seizure recurrence. Lancet 1988; 331:72126.
21. Dam A.M, Fuglsang-Frederiksen A., Svarreolsen U., Dam M. Late-onset epilepsy: etiologies, types of seizure, and value of clinical investigation, EEG, and computerized tomography scan. Epilepsia 1985; 26: 227-31.

22. Drury I., Beydoun A. Interictal epileptic form activity in elderly patients with epilepsy. Electroencephalogr. Clin. Neurophysiol 1998; 106: 369-73.

23. Ramsay RE, Rowan AJ, Pryor FM et al. Special considerations in treating the elderly patient with epilepsy. Neurology 2004; 62(Suppl 2):S24-S29.

24. Widdess-Walsh P, Sweeney BJ, Galvin R, McNamara B. Utilization and Yield of EEG in the Elderly Population. J Clin Neurophysiol 2005; 22: 253-55.

25. Christine J. Kilpatrick, Brian M. Tress, Christopher O'Donnell, Stephen C. Rossiter John L. Hopper. Magnetic Resonance Imaging and Late-Onset Epilepsy. Epilepsia 2007; 358-64.

26. Thomas R. Seizures and epilepsy in the elderly. Arch Intern Med 1997; 157: 605-17.

27. Li SC, Schoenberg BS, Wang CC, Cheng XM et al. Epidemiology of epilepsy in urban areas of the people's Republic of China. Epilepsia 1985; 26(5):391-94.

28. Aziz H, Ali SM, Frances P, Khan M I et al. Epilepsy in Pakistan: A Population-Based Epidemiologic Study Epilepsia 1994; 35:950-58.

29. Sirven J. Acute and chronic seizures in patients older than 60 years. Mayo Clinic Proceedings. 2001; 76:175-83. 